\title{
Comparison of tropospheric scintillation prediction models of the Indonesian climate
}

\author{
Cheng Yee Chen ${ }^{*}$ and Mandeep Jit Singh
}

\begin{abstract}
Tropospheric scintillation is a phenomenon that will cause signal degradation in satellite communication with low fade margin. Few studies of scintillation have been conducted in tropical regions. To analyze tropospheric scintillation, we obtain data from a satellite link installed at Bandung, Indonesia, at an elevation angle of $64.7^{\circ}$ and a frequency of $12.247 \mathrm{GHz}$ from 1999 to 2000. The data are processed and compared with the predictions of several well-known scintillation prediction models. From the analysis, we found that the ITU-R model gives the lowest error rate when predicting the scintillation intensity for fade at $4.68 \%$. However, the model should be further tested using data from higher-frequency bands, such as the K and Ka bands, to verify the accuracy of the model.
\end{abstract}

Keywords: Tropospheric scintillation; Ku band; Satellite communication; Tropical climate

\section{Background}

Tropospheric scintillation is receiving more attention because of the demand for higher bandwidth due to the congestion on the $\mathrm{C}$ and $\mathrm{Ku}$ bands. Higher-frequency bands tend to be affected by tropospheric scintillation, which is an event that causes the rapid fluctuation of the magnitude and phase of millimeter radio waves to occur in satellite communication systems. When the signal encounters turbulence in the atmosphere, rapid variations in the refractive index along the path will lead to fluctuations in the signal level received (Mandeep and Hassan 2004; Mandeep et al. 2006; Karasawa et al. 1988a). These fluctuations, called scintillations, are generally constant around the mean signal level. Tropospheric scintillation depends on the season and daily weather conditions. On satellite links, significant scintillation effects are mainly caused by strong turbulence in clouds and usually occur in the summer afternoon (Mandeep and Hassan 2004).

Tropospheric scintillation intensity has been proven to increase with high carrier frequency, low elevation angle, and small receiving antenna. In general, signal fade caused by rain attenuation on communication signals is more significant compared to signal fade caused by tropospheric scintillation. However, considerations regarding

\footnotetext{
* Correspondence: ant1986@rocketmail.com

Department of Electrical, Electronic and System Engineering, Faculty of Engineering and Built Environment, Universiti Kebangsaan Malaysia UKM, Bangi, Selangor Darul Ehsan 43600, Malaysia
}

tropospheric scintillation when designing the link budget become vital for low-fade-margin systems that operate at high frequency and low elevation angle (Mandeep et al. 2006). A satellite communication system that operates at a high frequency $(>10 \mathrm{GHz})$ and a low elevation angle $\left(<10^{\circ}\right)$ may experience more degradation from scintillation than from rain attenuation. Typically, satellite links above $10 \mathrm{GHz}$ may suffer from tropospheric scintillation fluctuations of up to several decibels peak-to-peak with duration of the scintillation events, of a few seconds.

Scintillation occurs under clear-sky conditions and during rain. However, distinguishing actual scintillation from rapid variations of rain attenuation in the presence of rain is not straightforward to Marzano and d'Auria (1998). In addition, it is of less interest to investigate scintillation under rainy conditions for low-availability satellite system design purposes because rain attenuation is usually much more pronounce than scintillation fades (Marzano et al. 1999; Ortgies 1993; Otung 1996; Otung and Savvaris 2006). For those reasons, only clear-weather scintillation is accounted for in this project (impairments such as rain attenuation and noise are eliminated). Noise was eliminated by visual inspection on all date sequence. Thus, accurate estimates of signal degradation due to this effect must be included in the design of satellite communication systems (Singh and Hassan 2003; Geoffroy et al. 1997; Kamp et al. 1997; Kamp 1998; Van De Kamp et al. 1999; Yu et al. 2006) (c) 2014 Chen and Singh; licensee Springer. This is an Open Access article distributed under the terms of the Creative Commons Attribution License (http://creativecommons.org/licenses/by/4.0), which permits unrestricted use, distribution, and reproduction in any medium, provided the original work is properly credited. 
Indonesia, like other Southeast Asian countries, is near the equator and has a hot and humid tropical climate and two monsoon seasons, one between October and February and the other from April to October; the first is characterized by thunderstorms. Temperatures and humidity are high throughout the year. This climate varies from those of European countries where the climate is cold and dry most of the year. The Karasawa model (Karasawa et al. 1988b), for example, was developed in Yamaguchi (Japan). Other models, such as the Otung model (Otung 1996) and the Van de Kamp model (Van De Kamp et al. 1999) were developed using a European database. Because a large variation exists between the climate in Europe and Indonesia, an analysis of the tropospheric scintillation prediction models against the measured scintillation intensity for Indonesia (tropical climate) is needed.

\section{Methods}

\section{Experimental setup}

Measurement site

The scintillation data are taken from a $12.247-\mathrm{GHz}$ JCSAT3 beacon at an elevation angle of $64.7^{\circ}$ at a sampling rate of $1 \mathrm{~s}$. The beacon is located at Bandung $\left(6.9^{\circ} \mathrm{S}\right.$, $\left.107.6^{\circ} \mathrm{E}\right)$. The data for this analysis were taken from January 1999 to December 2000. The beacon receiver has a sampling rate of $1 \mathrm{~Hz}$ which is sufficient to analyze tropospheric scintillation data. Temperature, humidity, wind direction, and speed were placed closed to the antenna used to measure the surface parameter. Rain rate was measured using a rain gauge.

\section{Data analysis}

Non-rain events were separated from the rain events for the experimental data. The rain events were determined with the use of a rain gauge. The clear-sky level was indicated by using a spectrum analyzer and a rain gauge whereby rain periods have been removed. The raw data were inspected visually to remove any spurious samples as much as possible resulting from loss of lock due to the satellite propellant saving option and satellite movement. The data were extracted by passing through a fifth-order high-pass Butterworth filter with a 0.04- $\mathrm{Hz}$ cutoff frequency based on performing a spectral analysis. After the filtering process, the resulting data consists of positive (enhancement) and negative (fade) scintillation amplitude fluctuations above the mean level. The scintillation intensity is calculated as the standard deviation of the amplitude fluctuations over $1 \mathrm{~min}$ (Garcia-del-Pino et al. 2012).

Further description of data processing is given in Mandeep (2011) and Mandeep et al. (2008). The probability of $89 \%$ of the samples was used in this analysis over the measurement period. Table 1 shows the ground station configuration for the JCSAT3 beacon.
Table 1 Satellite specifications

\begin{tabular}{lc}
\hline & Specifications \\
\hline Antenna height above sea level & $700 \mathrm{~m}$ \\
Beacon frequency & $12.247 \mathrm{GHz}$ \\
Elevation angle & $64.7^{\circ}$ \\
Polarization & Horizontal \\
Antenna configuration/azimuth angle & Offset parabolic/73.2 \\
Antenna diameter & $1.8 \mathrm{~m}$ \\
Satellite position & $128^{\circ} \mathrm{E}$ \\
Satellite ElRP & $50 \mathrm{dBW}$ \\
3-dB beamwidth & $0.95^{\circ}$ \\
\hline
\end{tabular}

\section{Tropospheric scintillation prediction models}

The measured scintillation data will be compared with nine tropospheric scintillation prediction models: the Karasawa, ITU-R, Otung, DPSP, STH2, STN2, Ortgies$\mathrm{N}$, Ortgies- $\mathrm{T}$, and Van de Kamp models (Table 2). The following parameters are used by many of the described models: $\sigma^{\text {ref }}$ is the standard deviation of the signal amplitude, $f$ is the operational frequency, $g(x)$ is the antenna averaging factor, $\theta$ is the antenna elevation angle, $H$ is the surface humidity, and $t$ is the surface temperature $\left({ }^{\circ} \mathrm{C}\right)$ (Mandeep and Hassan 2004).

\section{ITU-R tropospheric scintillation model}

The ITU-R P.618-9 (2007) model is based on indirect measurements, and the data were obtained from the International Telecommunication Union (ITU) data bank. The model is suitable for predictions in the elevation angle

\section{Table 2 Specifications of the scintillation models}

\begin{tabular}{|c|c|}
\hline Model & Specifications \\
\hline Karasawa & $\begin{array}{l}\text { 14- and 11-GHz satellite link, } \\
\text { elevation angle 6.5, diameter } \\
\text { of } 7.6 \text { m, Yamaguchi, Japan, } \\
\text { and } 1 \text { year of data (1988) }\end{array}$ \\
\hline ITU-R & DBSG5 database \\
\hline Otung & $\begin{array}{l}\text { 19.8-GHz satellite link, elevation } \\
\text { angle of 28.7, diameter } 7.6 \text { m, } \\
\text { Sparsholt, UK, and } 1 \text { year of } \\
\text { data (1996) }\end{array}$ \\
\hline DPSP, STN2, STH2 & $\begin{array}{l}\text { 18.7-, } 39.6-\text {, and } 49.5-\mathrm{GHz} \text { satellite } \\
\text { link, elevation angle of } 30.6 \text {, } \\
\text { diameter of } 1.8 \mathrm{~m}, \text { Milan, Italy, } \\
1 \text { year of data (1998) }\end{array}$ \\
\hline Ortgies-T, Ortgies-N & $\begin{array}{l}\text { 12.5-, 20-, and 30-GHz satellite link; } \\
\text { diameter of 0.6, 1.8, and } 3.7 \text { m; } \\
\text { Darmstadt, Germany, and } 1 \text { year } \\
\text { of data (1993) }\end{array}$ \\
\hline Van de Kamp & $\begin{array}{l}\text { 19.8- and 29.7-GHz satellite link, } \\
\text { elevation angle of 12.7, diameter } \\
\text { of } 1.8 \text { m, Helsinki, Finland, } 1 \text { year } \\
\text { of data (1998) }\end{array}$ \\
\hline
\end{tabular}


range of $40^{\circ}$ to $60^{\circ}$, the antenna diameters between 3 and $36 \mathrm{~m}$, and the frequency range of 7 to $14 \mathrm{GHz}$. The model is based on monthly (or longer) averages of temperature, $t\left({ }^{\circ} \mathrm{C}\right)$, and relative humidity, $H(\%)$, and it reflects the specific climate conditions of the site. Multipath fading for medium elevation angles below $50^{\circ}$ was considered. The measured data were based on a horizontally polarized beacon receiver, and the data from the vertically polarized receiver was not considered. The cumulative distribution of the fade tropospheric scintillation is given as

$$
\begin{aligned}
& \sigma_{\text {pre }}=\frac{\sigma_{\text {ref }} f^{7 / 12} g(x)}{(\sin \theta)^{1.2}} \\
& \operatorname{As}(p)=a(p) \cdot \sigma_{\text {pre }}(\mathrm{dB})
\end{aligned}
$$

where

$$
\begin{aligned}
& \sigma_{\text {ref }}=3.6 \times 10^{-3}+N_{\text {wet }} \times 10^{-4} \mathrm{~dB} \\
& N_{\text {wet }}=\frac{3,732 \mathrm{Hes}}{(273+T)^{2}} \\
& \text { es }=6.1121 \exp \left(\frac{17.502 T}{T+240.97}\right)(\mathrm{kPa}) \\
& g(x)=\sqrt{3.86\left(x^{2}+1\right)^{\frac{11}{12}} \times \sin \left[\frac{11}{6} \arctan \left(\frac{1}{x}\right)\right]-7.08 x^{5 / 6}} \\
& x=1.222 \frac{D_{\text {eff }}^{2} f}{L} \\
& D_{\text {eff }}=\sqrt{\eta} D m \\
& L=\frac{2 h_{\mathrm{L}}}{\sqrt{\sin ^{2} \theta+2.35 \times 10^{-4}}+\sin \theta}
\end{aligned}
$$

where $h_{\mathrm{L}}$ is the height of the turbulent layer; the value to be used is $h_{\mathrm{L}}=1,000 \mathrm{~m}$.

$$
\begin{array}{rl}
a(p)=-0.061 & *(\log p)^{3}+0.072 *(\log p)^{2}-1.71 \\
& *(\log p)+30.01 \%<p<50.0 \% .
\end{array}
$$

\section{DPSP tropospheric scintillation model}

The direct physical statistical prediction (DPSP) model was developed using the measurement data for 1 year from Louvain-la-Neuve in Belgium and Milan in Italy. The data were collected by the Olympus satellite beacon at frequencies of 12.5, 29.7, and $19.77 \mathrm{GHz}$. The antenna diameters for the antennas in Belgium and Italy are 1.8 and $1.5 \mathrm{~m}$, respectively. The elevation angles of the antennas are $27.60^{\circ}$ and $30.60^{\circ}$, with a post-processing sampling rate of $1 \mathrm{~Hz}$. A threshold value was imposed on the scintillation data because of the noise of the equipment, and any scintillation intensity above $0.04 \mathrm{~dB}$ was considered a scintillation event. For both models, the wet term refractive index was not considered because of the lack of humidity data. The DPSP model, as given in Marzano et al. (1999), is

$$
\begin{aligned}
\text { In } \sigma_{\text {pre }}^{2}= & \ln \left[g(x) \cdot f^{1.166}(\sin \theta)^{-2.4}\right] \\
& +[-16.95+0.1235 T] .
\end{aligned}
$$

\section{Karasawa tropospheric scintillation model}

The prediction by the Karasawa model is based on a year of data obtained at a low elevation angle with 14/ $11-\mathrm{GHz}$ wave propagation experiment at Yamaguchi, Japan, using the INTELSAT-V IOR (600E) satellite with a horizontally polarized beacon receiver. The satellite has a Cassegrain antenna with an elevation angle of $6.50^{\circ}$, a diameter of $7.6 \mathrm{~m}$, and a data sampling interval of $1 \mathrm{~s}$. The model is suitable for frequencies ranging from 7 to $14 \mathrm{GHz}$ and elevation angles from $40^{\circ}$ to $300^{\circ}$. Furthermore, the model accounts for the changes in fluctuation magnitudes associated with seasonal variations. This is performed using the linear regression of a monthly average signal standard deviation with a wet refractivity index, which is a function of the average local ground-level humidity and temperature, to account for the different climate zones. The vertically polarized beacon receiver scintillation data were not included when developing the model. The multipath fading and scintillation effect due to rain were considered. The model, as given in Karasawa et al. (1988a, b), is expressed as

$$
m=\sigma_{x, \text { ref }} \cdot \eta_{f} \cdot \eta_{\theta} \cdot \eta_{\mathrm{Da}}(\mathrm{dB}) .
$$

To predict fade scintillation, the following expression is used:

$$
\operatorname{As}(p)=a(p) \cdot m(\mathrm{~dB}) .
$$

To predict enhancement scintillation, the following expression is used:

$$
\operatorname{Es}(p)=e(p) \cdot m(\mathrm{~dB}) .
$$

In the above equations,

$$
\begin{aligned}
& \sigma_{x, \text { ref }}=0.15+5.2 \times 10^{-4} N_{\text {wet }}, \\
& \eta_{f}=\left({ }^{f} / 11.5\right)^{0.45}, \quad(16) \\
& \eta_{\theta}=\left(\sin 6.5^{\circ} / \sin \theta\right)^{1.3}, \theta \geq 5^{\circ}, \text { and } \\
& \eta_{\mathrm{Da}}=\sqrt{ } \frac{G(D)}{G(7.6)} .
\end{aligned}
$$


The time percentage factor enhancement is given by

$$
\begin{array}{rl}
e(p)=-0.0597 & *(\log p)^{3}-0.0835 *(\log p)^{2}-1.258 \\
& *(\log p)+2.672, \text { and } 0.01 \%<p<50.0 \% .
\end{array}
$$

The fade is given by

$$
\begin{array}{rl}
a(p)=-0.061 & *(\log p)^{3}+0.072 *(\log p)^{2}-1.71 \\
& *(\log p)+3, \text { and } 0.01 \%<p<50.0 \%
\end{array}
$$

\section{Ortgies scintillation model}

The Ortgies scintillation model is based in the Research Centre of Deutsche Bundespost Telekom with the scintillation data obtained since October 1989 at 12.5, 20, and $30 \mathrm{GHz}$ by using the Olympus satellite. The attenuation obtained was based on two antennas: the first was at $12.5 \mathrm{GHz}$ (1.8 $\mathrm{m}$ in diameter), and the second was for the $\mathrm{B} 1$ and $\mathrm{B} 2$ beacons at 20 and $30 \mathrm{GHz}(3.7 \mathrm{~m}$ in diameter), which were captured at Darmstadt. The signal fluctuations caused by tropospheric attenuation due to gases, clouds, and rain were separated with appropriate filtering. Variances in 1-min increments were calculated to represent the signal fluctuations known as scintillations. In $\sigma_{x}^{2}$, the Ortgies model assumed that short-term scintillation fluctuations follow a normal probability density function (pdf) and long-term scintillation follows lognormal pdf (Ortgies 1993). The models that were used in this paper are the Ortgies- $\mathrm{N}$ model that utilizes the mean wet component of the surface refractivity, $N_{\text {wet: }}$

$$
\begin{aligned}
\text { In } \sigma_{\text {pre }}^{2}= & \ln \left[g(x) \cdot f^{1.21}(\sin \theta)^{-2.4}\right]-13.45 \\
& +0.0462 N_{\text {wet }},
\end{aligned}
$$

and the Ortgies-T model that utilizes the mean surface temperature, $T$ :

$$
\begin{aligned}
\text { In } \sigma_{\text {pre }}^{2}= & \ln \left[g(x) \cdot f^{1.21}(\sin \theta)^{-2.4}\right]-12.5 \\
& +0.0865 T .
\end{aligned}
$$

\section{Otung scintillation model}

The Otung tropospheric scintillation model uses the Olympus satellite beacon at $19.7704 \mathrm{GHz}$ over a 1-year period from September 1992 to August 1993. The beacon is located at Sparsholt, UK, where the elevation angle is $28.74^{\circ}$. The scintillation data are collected using a $1.2-\mathrm{m}$ diameter beacon with a $10-\mathrm{Hz}$ sampling rate. Raw data were preprocessed through a high-pass filter with a cutoff frequency of $0.004 \mathrm{~Hz}$ to avoid attenuation of the signal that may lead to inaccurate processing. The mathematical model is similar to the ITU-R model, and the main difference is in the $\sigma_{\text {pre. }}$ The Otung model states that (Otung 1996)

$$
\sigma_{\text {pre }}=\frac{\sigma_{\text {ref }} f^{7 / 12} g(x)}{(\sin \theta)^{11 / 12}} .
$$

The fade and enhancement of scintillation are then computed with the negative and positive $X$, where $X$ for enhancement is

$$
X(P)_{+a}=3.1782 \sigma_{\text {pre }} \exp \left[\begin{array}{l}
-0.359654 p \\
-(0.272113-0.00438 p) \operatorname{In}(p)
\end{array}\right] .
$$

For fade, $X$ is given by

$$
X(P)_{-a}=3.6192 \sigma_{\text {pre }} \exp \left[\begin{array}{l}
-\frac{9.50142 \times 10^{-4}}{p} \\
-(0.40454+0.00285 p) \operatorname{In}(p)
\end{array}\right] .
$$

\section{Van De Kamp model}

The Van De Kamp model (Kamp model, in short) is an enhanced model that extended the Karasawa model to include both the surface layer and cloud scintillation. Both the Karasawa and the ITU-R model assume that most scintillation is caused by clear-air turbulence at ground level. This model is as shown below (Kamp 1998; Van De Kamp et al. 1999):

$$
\begin{aligned}
& \sigma_{\text {pre }}=\frac{\sigma_{\text {ref }} f^{0.45} g(x)}{(\sin \theta)^{1.3}} \\
& \sigma_{x, \text { ref }}=0.98 \times 10^{-4}\left(N_{\text {wet }}+Q\right)
\end{aligned}
$$

where

$$
Q=-39.2+56 \bar{W}_{\mathrm{hc}}
$$

where $W_{\mathrm{hc}}$ is the long-term average water content for heavy clouds.

The Kamp model changes the time percentage factor, and the enhancement is given by

$$
\begin{gathered}
E(p)=a 1(p) * \sigma_{\mathrm{pre}}-a 2(p) * \sigma_{\mathrm{pre}^{2}} \\
0.01 \%<p<20.0 \%
\end{gathered}
$$

and fade is given by

$$
\begin{aligned}
& a(p)=a 1(p) * \sigma_{\mathrm{pre}}+a 2(p) * \sigma_{\mathrm{pre}}^{2} \\
& 0.01 \%<p<20.0 \%
\end{aligned}
$$

where

$$
\begin{aligned}
a 1(p)= & -0.0515 *(\log p)^{3}+0.206 \\
& *(\log p)^{2}-1.81 *(\log p)+2.81
\end{aligned}
$$



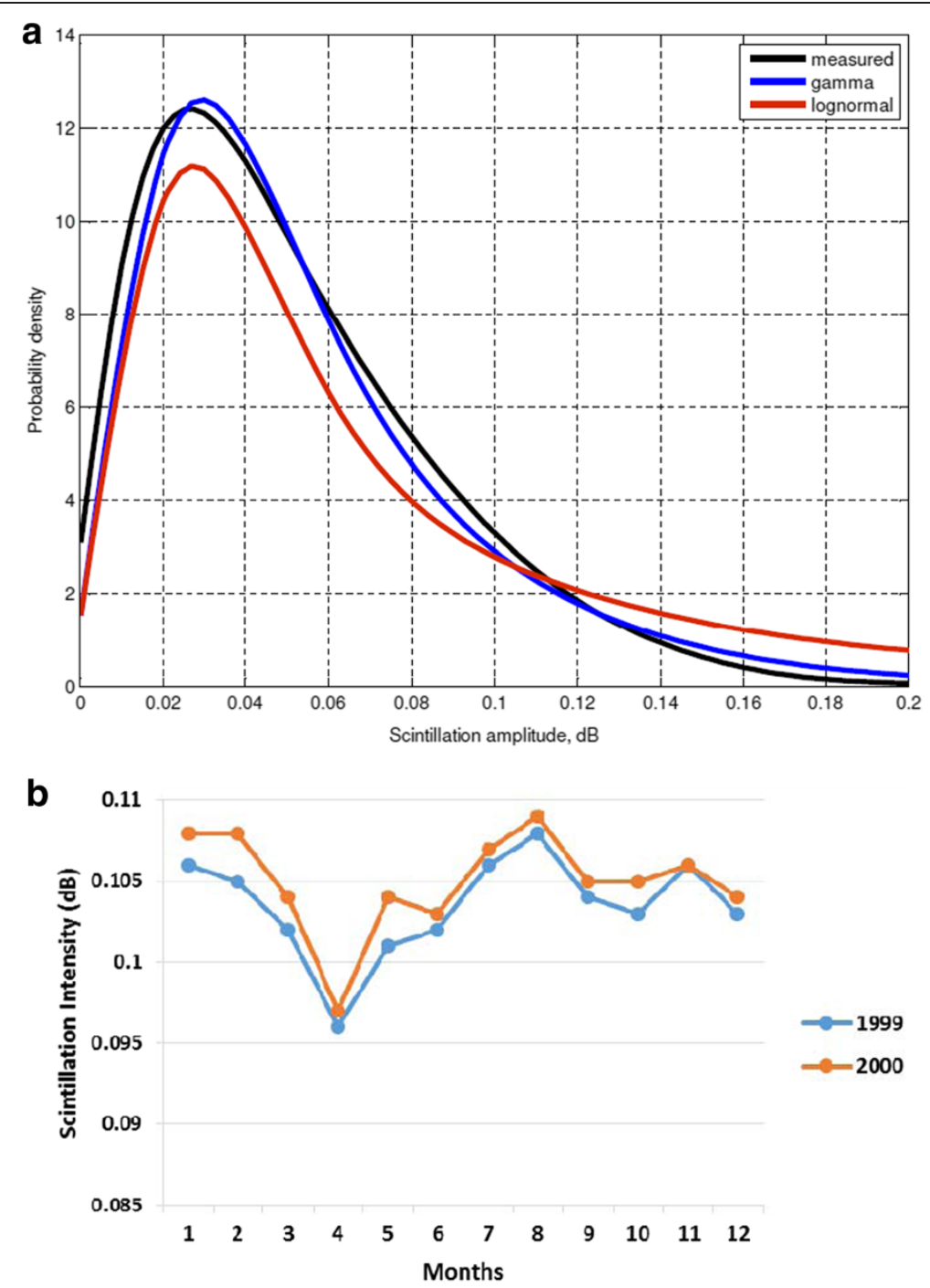

Figure 1 Long-term probability density and scintillation intensity for 3 years. (a) Long-term probability density of measured, lognormal and gamma scintillation amplitude. (b) Scintillation intensity for 3 years at the measurement site.

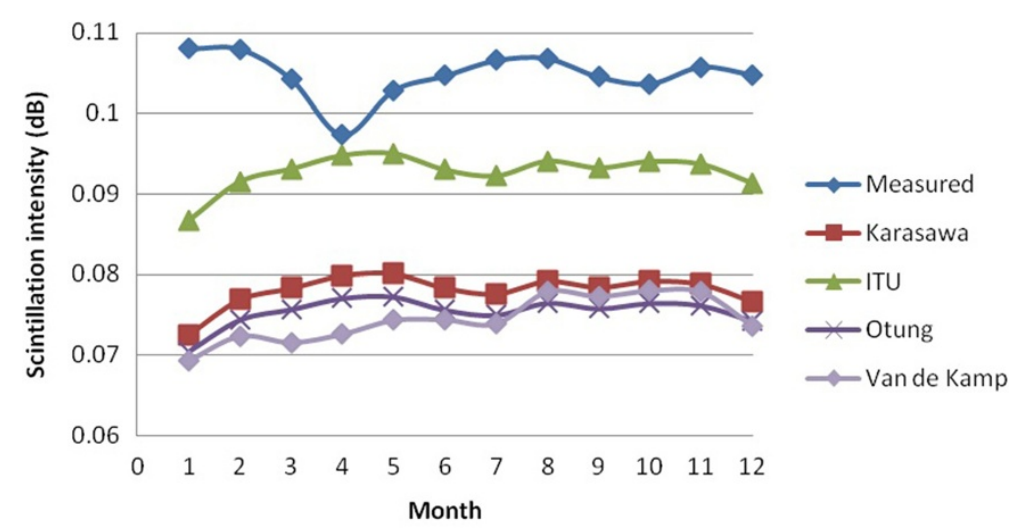

Figure 2 Comparison of scintillation intensity between measured data and data from prediction models in category 1. 


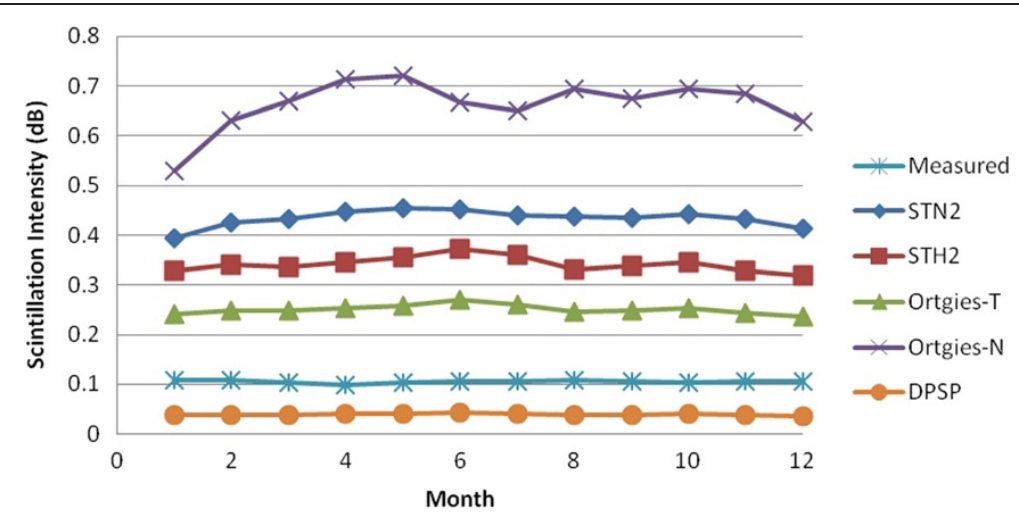

Figure 3 Comparison of scintillation intensity between measured data and data from prediction models in category 2.

$$
\begin{aligned}
a 2(p)= & -0.172 *(\log p)^{2}-0.454 *(\log p) \\
& +0.274 .
\end{aligned}
$$

\section{Marzano's STH2 and STN2 models}

The Marzano statistical temperature and humidity 2 (STH2) and statistical temperature and refractivity 2 (STN2) models are developed using the statistical multivariate regression method. The models are developed based on 10-year conventional radio-sounding observation (RAOB) and compared with $19.8-\mathrm{GHz}$ microwave slant link at an elevation angle of $30.6^{\circ}$. The models predict monthly mean logarithm of log-signal variance by scaling a normalized mean logarithm of log-signal variance with (Marzano and D'Auria 1998; Marzano et al. 1999)

$$
\begin{aligned}
\left\langle\ln \left(\sigma_{\text {pre }}{ }^{2}\right)\right\rangle= & \ln \left[g^{2}(x) \cdot k^{1.166}(\sin \theta)^{-\frac{11}{6}}\right] \\
& +\left\langle\ln \left(\sigma_{X^{n}}{ }^{2}\right)\right\rangle .
\end{aligned}
$$

STH2 is based on mean surface temperature, $T$, and relative humidity, $H$,

$$
\begin{aligned}
\left\langle\ln \left(\sigma_{X^{n}}{ }^{2}\right)\right\rangle= & -14.9504+0.1546\langle T\rangle \\
& +0.0747\langle H\rangle-0.0011\langle T\rangle^{2}-0.0005\langle H\rangle^{2} .
\end{aligned}
$$

\begin{tabular}{|c|c|c|c|c|c|c|c|c|c|}
\hline \multirow[t]{3}{*}{ Month } & \multicolumn{9}{|c|}{ Models } \\
\hline & Karasawa & ITU-R & Otung & DPSP & STN2 & STH2 & Ortgies-T & Ortgies-N & Kamp \\
\hline & \multicolumn{9}{|c|}{ \%error } \\
\hline January & -48.8 & -24.7 & -53.3 & -193.2 & 72.6 & 67.1 & 55.1 & 79.5 & -55.8 \\
\hline February & -40.3 & -18.0 & -45.1 & -179.8 & 74.6 & 68.2 & 56.6 & 82.9 & -49.2 \\
\hline March & -33.1 & -12.0 & -37.7 & -172.3 & 75.9 & 69.0 & 57.9 & 84.4 & -45.7 \\
\hline April & -21.9 & -2.7 & -26.3 & -146.2 & 78.2 & 71.8 & 61.5 & 86.4 & -34.1 \\
\hline May & -28.4 & -8.2 & -33.1 & -152.9 & 77.3 & 70.9 & 60.1 & 85.7 & -38.4 \\
\hline June & -33.5 & -12.5 & -38.4 & -141.7 & 76.8 & 71.8 & 61.2 & 84.3 & -40.6 \\
\hline July & -37.3 & -15.5 & -42.1 & -158.6 & 75.8 & 70.3 & 59.1 & 83.6 & -44.2 \\
\hline August & -34.9 & -13.5 & -39.6 & -182.0 & 75.5 & 67.7 & 56.5 & 84.6 & -37.1 \\
\hline September & -33.2 & -12.1 & -37.9 & -170.6 & 76.0 & 69.1 & 58.0 & 84.5 & -35.2 \\
\hline October & -30.9 & -10.2 & -35.6 & -163.5 & 76.6 & 69.9 & 58.9 & 85.1 & -32.9 \\
\hline November & -34.1 & -12.9 & -38.8 & -182.1 & 75.5 & 67.8 & 56.6 & 84.6 & -35.8 \\
\hline December & -36.6 & -14.7 & -41.1 & -190.2 & 74.7 & 67.1 & 55.9 & 83.3 & -42.2 \\
\hline
\end{tabular}

STN2 is based on mean surface temperature, $T$, and refractivity, $N_{\text {wet, }}$

Table 3 Comparison of the scintillation intensity percentage errors for each month of the average years 
Table 4 Overall means, standard deviations, and RMS values for the measurement site over a 2-year period

\begin{tabular}{lccccccccc}
\hline & \multicolumn{10}{c}{ Models } \\
\cline { 2 - 10 } & Karasawa & ITU-R & Otung & DPSP & STN2 & STH2 & Ortgies-T & Ortgies-N & Kamp \\
\hline Mean & -48.8 & -24.7 & -53.3 & -193.2 & 72.6 & 67.1 & 55.1 & 79.5 & -55.8 \\
Standard deviation & 6.50 & 5.30 & 6.52 & 16.97 & 1.43 & 1.71 & 2.09 & 1.71 & 6.85 \\
RMS & 49.3 & 25.2 & 53.7 & 194.0 & 72.6 & 67.1 & 55.2 & 79.6 & 56.2 \\
\hline
\end{tabular}

$$
\begin{aligned}
\left\langle\ln \left(\sigma_{X^{n}}^{2}\right)\right\rangle= & -12.3889+0.1300\langle T\rangle \\
& +0.0151\left\langle N_{\text {wet }}\right\rangle-0.0016\langle T\rangle^{2} .
\end{aligned}
$$

\section{Results and discussion}

Figure 1a shows the long-term probability density of scintillation amplitude for 2 years whereby both lognormal and gamma distributions have similar shapes. The pdf has a slightly greater spread in the tail (lower kurtosis) than a Gaussian distribution and positive skew for long observational experimental data. The skewness is observed for the strongest intensities, which is also usual in the absence of rain due to the cumulus clouds that cause a burst of strong scintillation during the event of cumulus clouds crossing the path. The gamma model proposed by Karasawa et al. (1988b) proved to provide a good performance for dry scintillation and the lognormal departs from the pdf-measured scintillation intensity. Figure $1 \mathrm{~b}$ shows the year-to-year measurement, where 1999 was a La Niña year, which lengthens the rainy season and shortens the dry season. There were not much of differences in the year-to-year variation for the entire percentage of time with a small variation of $0.002 \mathrm{~dB}$ on an average as given below. This is because the scintillation amplitude calculation was done during clear sky (absence of rain and spurious spikes).

The performances of the scintillation prediction models are analyzed for both the fade and enhancement scintillation. The scintillation intensity for every model is calculated using the formulas provided above. For a certain percentage of time (from $0.01 \%$ to $1 \%$ of the year), for which data are available, the percentage relative error, $E_{\text {rel }}$ (\%) between the predicted value and the measured value is calculated (Mandeep et al. 2011):

$$
E_{\text {rel }}=\left[\left(\chi_{\text {predicted }}-X_{\text {measured }}\right) / \chi_{\text {measured }}\right] \times 100 \text {. }
$$

The mean error, $\mu_{e}$, and standard deviation, $\sigma_{e}$, are used to calculate the root-mean-square, $D_{e}$ (RMS). The parameter is defined as follows:

$$
D_{e}=\left[\left(\mu_{e}\right)^{2}+\left(\sigma_{e}\right)^{2}\right]^{1 / 2} \text {. }
$$

\section{Comparison of monthly scintillation intensity}

In this paper, the mean monthly scintillation intensity of the measured data is calculated for the years 1999 to 2000. The calculated scintillation intensity data from the JCSAT3 satellite are compared with all the scintillation prediction models mentioned above. The models are

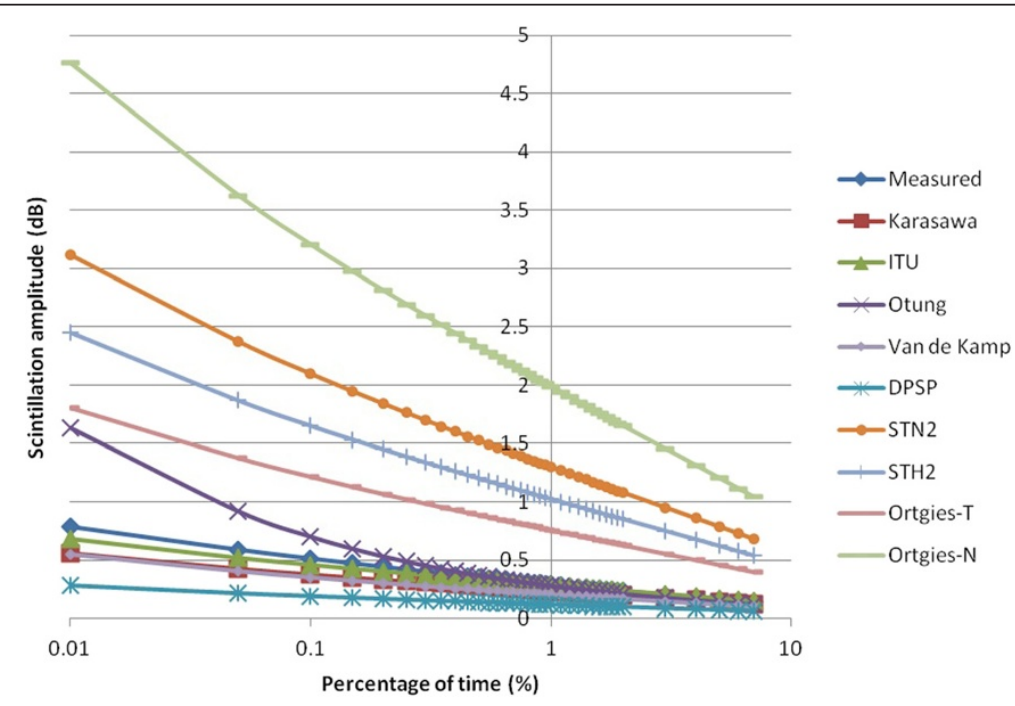

Figure 4 Comparison between the predicted and the measured scintillation intensity (fade). 


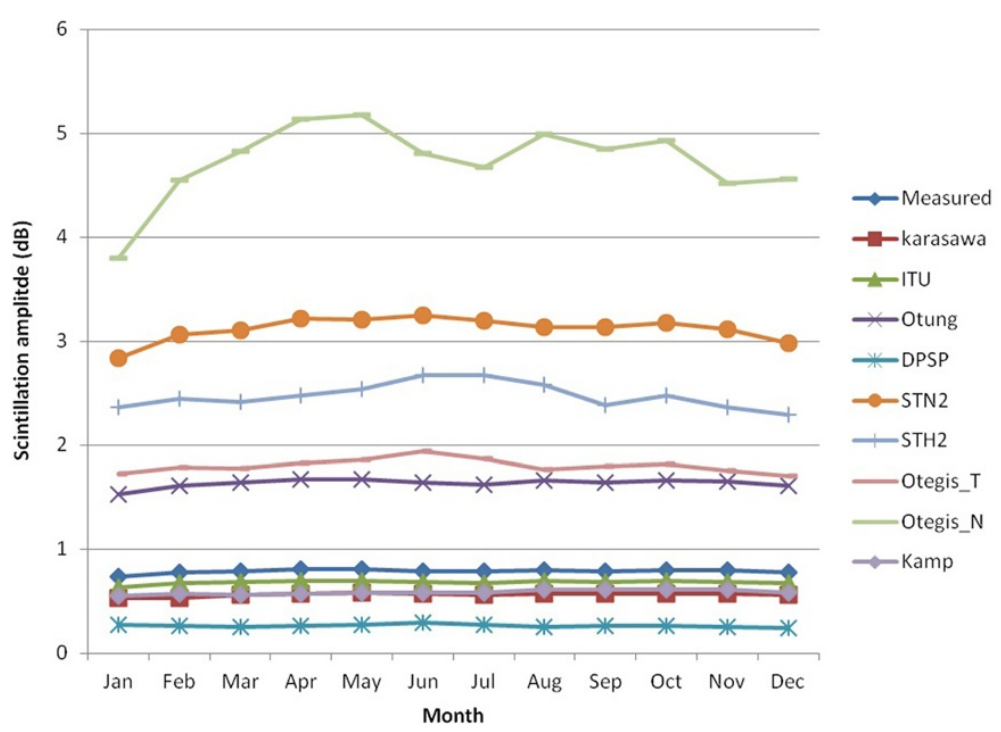

Figure 5 Comparison between the predicted and the measured data for the fade scintillation at $0.01 \%$.

divided into two categories. In category 1, the Karasawa, ITU-R, Otung, and Kamp models predict the variance of the signal log-amplitude. In category 2, the DPSP, STN2, $\mathrm{STH} 2$, Ortgies-T, and Ortgies- $\mathrm{N}$ models predict the logarithm of the variance of the signal log-amplitude. Figures 2 and 3 show the comparison of the mean monthly scintillation intensity prediction between 1999 and 2000 for categories 1 and 2, respectively.

From Figure 2, we can see that all of the models underestimate the scintillation intensity, but the data do not vary significantly from the measured data. Referring from Tables 3 and 4, the ITU-R model has the best prediction between the studied time frame - the RMS error rate is only $25.2 \%$ - while the Karasawa model gives the second best prediction with an error rate of $49.3 \%$. Figure 3 shows the prediction models in category 2, which used the logarithm of the variance of the signal log-amplitude, and the data showed large differences compared with the measured data.
The DPSP model gives the highest RMS error rate at $194 \%$, compared to the other models. The error rate and root-mean-square error are shown in Tables 3 and 4 . Comparing Figures 2 and 3, we can clearly see that models that predict the variance of the signal log-amplitude are more accurate in predicting the scintillation intensity for the climate in Bandung. This is because scintillation in the climate in Bandung follows a gamma distribution as shown in Figure 1, and the prediction models of category 1 are developed assuming that scintillation follows a gamma distribution. The prediction models in category 2 assume that the scintillation follows a lognormal distribution. This assumption is only true for the climates in Europe and not for the global climate.

\section{Comparison of mean scintillation amplitude}

Predictions of the monthly scintillation amplitude are calculated for the average measurement years at $0.01 \%$ of the time. We introduced a correlation in the analysis

Table 5 Mean RMS error and correlation for fade scintillation

\begin{tabular}{|c|c|c|c|c|c|c|c|c|}
\hline \multirow[t]{2}{*}{ Models } & \multicolumn{2}{|c|}{$\%$ error } & \multicolumn{2}{|c|}{ Correlation } & \multicolumn{2}{|c|}{ Standard deviation } & \multicolumn{2}{|c|}{ \%RMS } \\
\hline & ITB & USM & ITB & USM & ITB & USM & ITB & USM \\
\hline Karasawa & 4.2 & -62.3 & 0.9997 & 0.9588 & 6.92 & 18.9 & 7.0 & 65.1 \\
\hline ITU-R & -3.7 & -56.4 & 0.9997 & 0.9658 & 4.17 & 22.4 & 4.2 & 60.7 \\
\hline Otung & 4.5 & 32.5 & 0.9572 & 0.9814 & 11.2 & 15.9 & 11.1 & 36.2 \\
\hline Kamp & 43.4 & -50.9 & 0.9997 & 0.9724 & 1.22 & 25.4 & 41.3 & 56.9 \\
\hline DPSP & -153.6 & -69.1 & 0.9997 & 0.998 & 10.7 & 15.9 & 139.5 & 70.9 \\
\hline STN2 & 77.2 & 81.3 & 0.9997 & 0.992 & 0.96 & 23.4 & 74.8 & 84.6 \\
\hline STH2 & 71.1 & 75.6 & 0.9997 & 0.994 & 1.22 & 18.4 & 68.1 & 77.8 \\
\hline Ortgies-T & 60.6 & 92.6 & 0.9997 & 0.994 & 1.66 & 26.1 & 56.5 & 96.2 \\
\hline Ortgies-N & 85.1 & 85.4 & 0.9997 & 0.995 & 0.63 & 22.8 & 83.5 & 88.4 \\
\hline
\end{tabular}




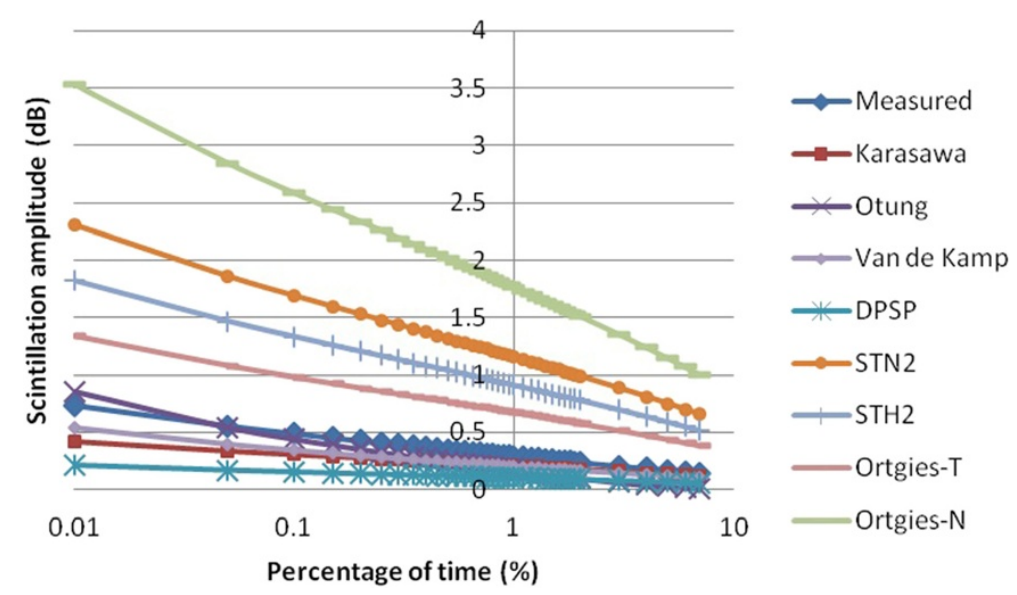

Figure 6 Comparison between the predicted and the measured scintillation intensity (enhancement).

in the form of a statistical parameter describing the degree of the relationship between two variables. We compared the correlation output for each of the prediction models with the measured tropospheric scintillation data. For positive values, there is a tendency for an interrelation to exist between either data or a positive relationship with the measured data and vice versa for negative values.

To calculate the percentage of time for both fade and enhancement scintillation, the Karasawa, Otung, and Kamp models provide equations to calculate both fade and enhancement scintillation. The ITU-R model only provides a fade scintillation equation to calculate the scintillation amplitude. Note that we show all the results in terms of scintillation amplitude, converting the scintillation amplitude predictions (Karasawa and ITU-R) by means of the discretization of the associated cumulative distribution functions $(\mathrm{CDF})$ and making the discrete probability sum.

For fade scintillation, the Kamp, DPSP, STN2, STH2, Ortgies- $\mathrm{T}$, and Ortgies- $\mathrm{N}$ models have a large variance in the prediction compared with the measured data, which is shown in Figures 4 and 5. All of these models gave high percentage error and RMS error above $40 \%$. This could be caused by the scintillation measured in the presence of clouds and during rainfall which is caused by mechanisms different from those in dry scintillation and these models that were developed based on different frequency dependences. The impact on frequency power exponent values obtained through measurement sites for these models utilizing large antennas and low elevation angles could have contributed to the over- or under-prediction of these models towards the measurement sites.

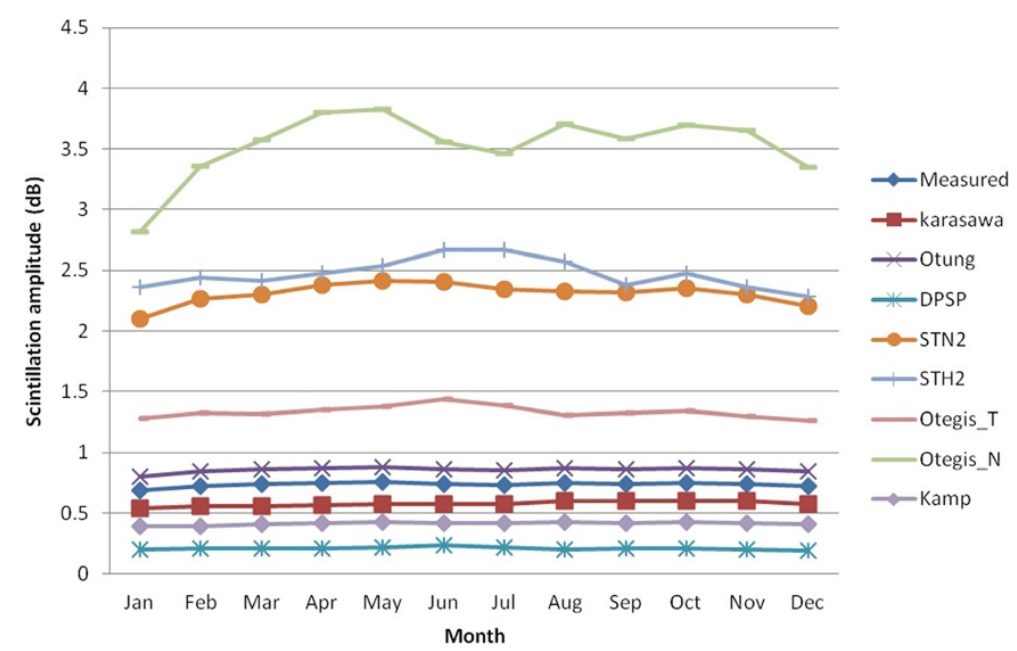

Figure 7 Comparison between the predicted and the measured data for enhancement scintillation at $0.01 \%$. 
Table 6 Mean RMS error and correlation for enhancement scintillation

\begin{tabular}{|c|c|c|c|c|c|c|c|c|}
\hline \multirow[t]{2}{*}{ Models } & \multicolumn{2}{|c|}{$\%$ error } & \multicolumn{2}{|c|}{ Correlation } & \multicolumn{2}{|c|}{ Standard deviation } & \multicolumn{2}{|c|}{ \%RMS } \\
\hline & ITB & USM & ITB & USM & ITB & USM & ITB & USM \\
\hline Karasawa & 1.4 & -64.4 & 0.9964 & 0.9541 & 12.6 & 18.5 & 12.7 & 67 \\
\hline Otung & 2.6 & 38.4 & 0.9955 & 0.9622 & 32.4 & 14.9 & 32.5 & 41.2 \\
\hline Kamp & 34.9 & -53.8 & 0.9988 & 0.9717 & 2.32 & 24.2 & 34.9 & 59 \\
\hline DPSP & 166.5 & -70.9 & 0.9964 & 0.9951 & 20.4 & 15.1 & 167.8 & 72.5 \\
\hline STN2 & 68.1 & 73.1 & 0.9964 & 0.994 & 1.84 & 47.5 & 68.1 & 87.2 \\
\hline STH2 & 59.5 & 67.2 & 0.9964 & 0.994 & 2.33 & 42.3 & 59.6 & 79.4 \\
\hline Ortgies-T & 44.9 & 88.1 & 0.9964 & 0.995 & 3.18 & 47.5 & 45 & 100.1 \\
\hline Ortgies-N & 79.1 & 78.9 & 0.9964 & 0.995 & 1.2 & 49.4 & 79.1 & 93.1 \\
\hline
\end{tabular}

The best model is the ITU-R model for Institute Technology Bandung (ITB), which predicts $0.67 \mathrm{~dB}$ for $0.01 \%$ of the time, when the measured scintillation for $0.01 \%$ of the time is $0.78 \mathrm{~dB}$, followed by the Karasawa model, which predicts $0.56 \mathrm{~dB}$. The error rates for the ITU-R and Karasawa models are $-3.7 \%$ and $4.2 \%$, respectively, as shown in Table 5. The Otung model also gave a good prediction which has a lower error rate and RMS of $4.5 \%$ and $11.1 \%$, respectively. However, the ITU-R and Karasawa models have overestimation results over the measured data for smaller values of $N_{\text {wet }}$. The best model for Universiti Sains Malaysia (USM) is Otung, which predicts a RMS value of $36.2 \%$, followed by Kamp, which gives a RMS error of $56.9 \%$ for the fade signal.

From Figure 4, the Otung model tends to overestimate the measured data for a lower percentage of time due to high $N_{\text {wet }}$ values. The poor comparison at a lower percentage of time which could be due to the effect of rain present at a small percentage of time has been excluded. Most of these models are based not only on clear-air signal fluctuation.

Figure 6 shows that for 97\% of the time, weak fluctuation of scintillation occurs with amplitude at about $0.3 \mathrm{~dB}$. Above this threshold, strong scintillation fade (Figure 4) occurs frequently than enhancement with the same magnitude. For enhancement scintillation, the overall distribution pattern is the same. Five models DPSP, STN2, STH2, Ortgies-T, and Ortgies-N - gave higher RMS values compared to the other models. The Karasawa model gives the best prediction of $0.50 \mathrm{~dB}$ compared with $0.72 \mathrm{~dB}$ for measured data at $0.01 \%$ of the time, as shown in Figures 6 and 7. The Karasawa model gives $1.4 \%$ for the mean error rate, 0.9964 correlation, and $12.7 \%$ for RMS. The second best model for

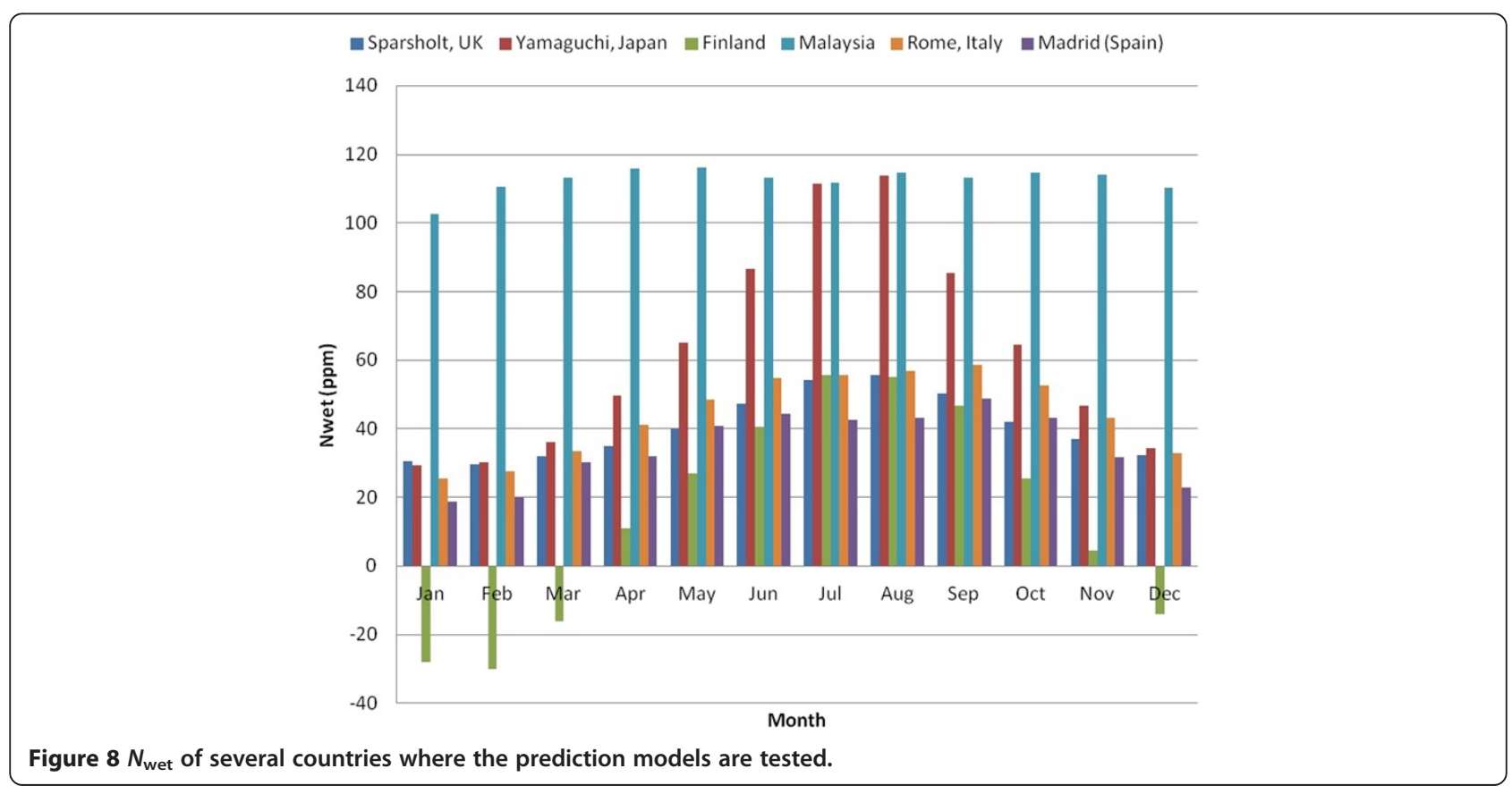


enhancement scintillation is the Otung model. The Otung time percentage enhancement equation gives a percentage error and RMS value of $2.6 \%$ and $32.5 \%$, respectively, as shown in Table 6.

Mandeep et al. (2011) conducted measurement at USM during the El Niño year with lengthened dry season. The measurement site is at $57 \mathrm{~m}$ above sea level compared to ITB which is at $700 \mathrm{~m}$ above sea level and during the La Niña year. The antenna elevation angles at USM and ITB are at $40.10^{\circ}$ and $64.70^{\circ}$ with antenna diameters of 2.4 and $1.8 \mathrm{~m}$, respectively, which highlights that the scintillation amplitude decreases as the elevation angle increases and increases as the antenna diameter increases. For example, at $0.1 \%$ of the time, the fade scintillation amplitude is $1.3 \mathrm{~dB}$ at USM and $0.5 \mathrm{~dB}$ at ITB. The average temperatures at USM and ITB were around $27^{\circ} \mathrm{C}$ and $23^{\circ} \mathrm{C}$, respectively, during the measured years. This indicates that the scintillation intensity reduces as the temperature reduces. Overall, the findings show that the elevation angle, altitude, and temperature do affect the intensity of tropospheric scintillation.

The ITU-R model gives the best prediction among the models because the scintillation model is developed using databases from all over the world. The regression on the time percentage factor is performed by comparing data from the DBSG5 database that consists of weather data over Asia Pacific, North and South America, and European countries. The Karasawa model is developed using a database where $N_{\text {wet }}$ varies from 20 to 130 ppm. From Figure 8, we can see that Bandung will have the wet term at approximately 100 to $115 \mathrm{ppm}$ and only Yamaguchi, Japan, where the Karasawa model originates, gets the same reading for the wet term. However, the RMS error in predicting the scintillation intensity is quite high. This may be because the Karasawa model was not tested with a high elevation angle $\left(40.1^{\circ}\right)$ and a small antenna diameter $(2.4 \mathrm{~m})$. The elevation angles and antenna diameters in the database were only from $4^{\circ}$ to $30^{\circ}$ and from 3 to $36.6 \mathrm{~m}$, respectively. This suggests that the time factor percentage model needed to be improved to accurately predict the scintillation intensities for tropical regions.

The error rates in the other scintillation prediction models tested in this experiment were very high and not suitable for predicting the scintillation intensity. From Figure 8, we can see that European countries have very low $N_{\text {wet }}$ values throughout the year. Countries like the UK, Italy, and Spain have average $N_{\text {wet }}$ values of less than $40 \mathrm{ppm}$. Models like DPSP, STH2, STN2, Ortgies$\mathrm{T}$, and Ortgies- $\mathrm{N}$ have difficulty predicting the scintillation for Bandung where the average $N_{\text {wet }}$ is approximately $110 \mathrm{ppm}$. The regression of these models is conducted using limited data, and the meteorology parameter is not tested against the data from other climate regions. Therefore, these models cannot be applied globally, especially to tropical countries like Bandung.

\section{Conclusions}

A review and evaluation of currently existing tropospheric scintillation prediction models have been presented in this paper. The prediction models are compared with the data obtained from the 12.247-GHz JCSAT3 beacon slant path at a satellite earth station, which is located at Bandung. The measurement from the satellite earth station confirmed that the ITU-R model gives the best scintillation intensity predictions for countries that have tropical climates.

\section{Competing interests}

The authors declare that they have no competing interests.

\section{Authors' contributions}

CYC analyzed the data and plotted the figures and tables. MJS drafted the paper and revised the paper based on the reviewers' comments. Both authors read and approved the final manuscript.

\section{Acknowledgements}

The authors would like to acknowledge the Universiti Kebangsaan Malaysia and the Association of Radio Industries and Businesses (ARIB) of Japan for providing the data in the form of a CD.

Received: 13 February 2014 Accepted: 12 June 2014

Published: 2 July 2014

\section{References}

Geoffroy P, Marzano FS, D'auria G, Riva C, Vanhoenacker-Janvier D (1997) Evaluation of statistical models for clear air scintillation prediction using Olympus satellite measurements. Int J Satellite Comm 15:73-88

International Telecommunication Union (2007) ITU-R P.618-9. Propagation data and prediction methods required for the design of Earth-space telecommunication systems. ITU, Geneva

Kamp MMJL (1998) Asymmetric signal level distribution due to tropospheric scintillation. Elec Let 34(11):1145-1146

Kamp MMJL, Tervonen JK, Salonen ET (1997) Tropospheric scintillation measurements and modelling in Finland. Paper presented at the tenth international conference on antennas and propagation. Edinburgh. 14-17 Apr 1997

Karasawa Y, Yamada M, Allnutt JE (1988a) A new prediction method for tropospheric scintillation on Earth-space paths. IEEE Trans Ant Prop 36(11):1608-1614

Karasawa Y, Yasukawa K, Yamada M (1988b) Tropospheric scintillation in the 14/11-GHz bands on Earth-space paths with low elevation angles. IEEE Trans Ant Prop 36(4):563-569

Mandeep JS (2011) Extracting of tropospheric scintillation propagation data from Ku-band satellite beacon. Int J Phy Sci 6(11):2649-2653

Mandeep JS, Hassan SIS (2004) Comparison of 1-minute rainfall rate distribution for tropical and equatorial climates. Space Commun 19:193-198

Mandeep SJS, Syed ISH, Kiyoshi I, Kenji T, Mitsuyoshi I (2006) Analysis of tropospheric scintillation intensity on earth to space in Malaysia. Amer J App Sci 3(9):2029-2032

Mandeep JS, Hassan SIS, Ain MF, Igarashi K (2008) Tropospheric scintillation measurement in Malaysia at Ku-band. J Electr Wav App 22(8-9):1063-1070

Mandeep JS, Anthony CCY, Abdullah M, Tariqul M (2011) Comparison and analysis of tropospheric scintillation models for Northern Malaysia. Acta Astro $69(1-2): 2-5$

Marzano FS, d'Auria G (1998) Model-based prediction of amplitude scintillation variance due to clear-air tropospheric turbulence on Earth-satellite microwave links. IEEE Trans Ant Prop 46(10):1506-1518

Marzano FS, Carlo R, Alessio B, Fabio C (1999) Assessment of model-based scintillation variance prediction on long-term basis using Italsat satellite measurements. Int J Satellite Comm 17(1):17-36

Ortgies G (1993) Frequency dependence of slant-path amplitude scintillations. Elec Let 29(25):2219-2220 
Otung IE (1996) Prediction of tropospheric amplitude scintillation on a satellite link. IEEE Trans Ant Prop 44(12):1600-1608

Otung IE, Savvaris A (2006) Estimating tropospheric scintillation intensity on earth-space propagation paths. Elec Let 42(7):381-382

Garcia-del-Pino P, Riera JM, Benarroch A (2012) Tropospheric scintillation with concurrent rain attenuation at $50 \mathrm{GHz}$ in Madrid. IEEE Trans Ant Prop 60(3):1578-1583

Singh MSJ, Hassan SIS (2003) Probability density functions of tropospheric amplitude scintillation on a satellite link. Paper presented at the 4th national conference on telecommunication technology. Shah Alam. 14-15 Jan 2003

Van De Kamp MMJL, Tervonen JK, Salonen ET, Poirares Baptista JPV (1999) Improved models for long-term prediction of tropospheric scintillation on slant paths. IEEE Trans Ant Prop 47(2):249-260

Yu P, Glover I, Watson PA, Davies OT, Ventouras S, Wrench C (2006) Review and comparison of tropospheric scintillation prediction models for satellite communications. Int J Satellite Comm 24(4):283-302

doi:10.1186/1880-5981-66-64

Cite this article as: Chen and Singh: Comparison of tropospheric scintillation prediction models of the Indonesian climate. Earth, Planets and Space 2014 66:64.

\section{Submit your manuscript to a SpringerOpen ${ }^{\circ}$ journal and benefit from:}

- Convenient online submission

- Rigorous peer review

- Immediate publication on acceptance

- Open access: articles freely available online

- High visibility within the field

- Retaining the copyright to your article

Submit your next manuscript at $\gg$ springeropen.com 